\title{
Correction: Assessment of Microstressors in Adults: Questionnaire Development and Ecological Validation of the Mainz Inventory of Microstressors
}

Andrea Chmitorz ${ }^{1,2}$, PhD, MPH; Karolina Kurth ${ }^{1,3,4}$, MSc; Lara K Mey ${ }^{1,3,4}$, MSc; Mario Wenzel $^{3,4}$, PhD; Klaus Lieb ${ }^{1,4}$, MD, PhD; Oliver Tüscher ${ }^{1,4^{*}}, \mathrm{MD}, \mathrm{PhD}$; Thomas Kubiak ${ }^{3,4^{*}}, \mathrm{PhD}$; Raffael Kalisch ${ }^{4,5^{*}}, \mathrm{PhD}$

${ }^{1}$ Department of Psychiatry and Psychotherapy, University Medical Center Mainz, Mainz, Germany

${ }^{2}$ Faculty of Social Work, Health Care and Nursing Sciences, Esslingen University of Applied Sciences, Esslingen, Germany

${ }^{3}$ Health Psychology, Institute for Psychology, Johannes Gutenberg University, Mainz, Germany

${ }^{4}$ Leibniz Institute for Resilience Research, Mainz, Germany

${ }^{5}$ Neuroimaging Center, University Medical Center, Mainz, Germany

*these authors contributed equally

\section{Corresponding Author:}

Andrea Chmitorz, PhD, MPH

Faculty of Social Work, Health Care and Nursing Sciences

Esslingen University of Applied Sciences

Flandernstraße 101

Esslingen

Germany

Phone: 497113974732

Email: andrea.chmitorz@hs-esslingen.de

\section{Related Article:}

Correction of: https://mental.jmir.org/2020/2/e14566/

(JMIR Ment Health 2020;7(5):e18626) doi: 10.2196/18626

The authors of "Assessment of Microstressors in Adults: Questionnaire Development and Ecological Validation of the Mainz Inventory of Microstressors" (JMIR Ment Health 2020;7(2):e14566) noticed that the equal contribution footnote was missing from the author list.

This has been amended to indicate that authors Oliver Tüscher, Thomas Kubiak, and Raffael Kalisch all contributed equally.
The correction will appear in the online version of the paper on the JMIR website on May 4, together with the publication of this correction notice. Because this was made after submission to PubMed, PubMed Central, and other full-text repositories, the corrected article has also been resubmitted to those repositories.

This is a non-peer-reviewed article. Submitted 13.03.20; accepted 16.03.20; published 04.05.20.

Please cite as:

Chmitorz A, Kurth K, Mey LK, Wenzel M, Lieb K, Tüscher O, Kubiak T, Kalisch R

Correction: Assessment of Microstressors in Adults: Questionnaire Development and Ecological Validation of the Mainz Inventory of Microstressors

JMIR Ment Health 2020;7(5):e18626

URL: https://mental.jmir.org/2020/5/e18626

doi: $10.2196 / 18626$

PMID: $\underline{32365047}$

(C)Andrea Chmitorz, Karolina Kurth, Lara K Mey, Mario Wenzel, Klaus Lieb, Oliver Tüscher, Thomas Kubiak, Raffael Kalisch. Originally published in JMIR Mental Health (http://mental.jmir.org), 04.05.2020. This is an open-access article distributed under the terms of the Creative Commons Attribution License (https://creativecommons.org/licenses/by/4.0/), which permits unrestricted use, distribution, and reproduction in any medium, provided the original work, first published in JMIR Mental Health, is properly 
cited. The complete bibliographic information, a link to the original publication on http://mental.jmir.org/, as well as this copyright and license information must be included. 